\title{
REFERENCE STANDARDS IN A PHARMACEUTICAL LABORATORY: OCCUPATIONAL EXPOSURE LIMITS AND QUALITATIVE EVALUATION
}

\author{
LÍVIA DE MARTIN LAZZARI, BRUNO VIANNA DO AMARAL \& PATRÍCIA DA CRUZ CUNHA \\ Candido Mendes University, Brazil
}

\begin{abstract}
Environmental risks in workplaces are often underestimated, particularly chemical risks because they require specific technical knowledge. In an industrial pharmaceutical laboratory, many substances may become a risk to workers' health. A qualitative evaluation book, published by Jorge Duprat Figueiredo Foundation for Safety and Occupational Medicine (Fundacentro) in 2012, uses the Globally Harmonized System of Classification and Labelling of Chemicals (GHS) to evaluate the chemicals toxicity. According to this methodology, the substances are divided into six groups. Groups A to E indicate health damage caused by inhalation or ingestion of substances. Being the most toxic allocated in category E, and less toxic or without GHS classification, covered by classification A. S group covers chemicals that can cause damage when in contact with skin or eyes. In this work, the Reference Standards (RS) of an industrial pharmaceutical laboratory were analysed by the mentioned methodology and quantitatively by exposure limits listed by American Conference of Governmental Industrial Hygienists (ACGIH) in 2014 and Brazilian Regulatory Norm number 15 (NR-15). The RS (357 units) were classified; 8.4\% presented some limit described by ACGIH 2014 and 3.9\% have some exposure limit informed by the NR-15. For the RS classified as D or E (highly toxic), only $4.2 \%$ have substances cited by the NR-15 and 12.6\% have substances listed by ACGIH 2014. In the qualitative evaluation, $43.4 \%$ of the RS presented risks when in contact with skin (S group). Only $2.5 \%$ have this risk by ACGIH and $0.8 \%$ by NR-15. The results showed that for a good recognition of chemical hazards, quantitative and qualitative analysis must be done together. Several substances have no quantitative limits and their toxicological effects are unknown, making the purely quantitative analysis insufficient to ensure the workers' health and safety.
\end{abstract}

Keywords: GHS, ACGIH, NR-15, qualitative analysis, quantitative analysis.

\section{INTRODUCTION}

Despite several issues that business owners confront every day, the employees' health and safety cannot be neglected. Thus, it is necessary to develop a methodology to manage the occupational risks in the company - an essential issue for any industry, or even commerce, to achieve excellence in their business. Another point that justifies this is the legal consequence for not complying with the legislation. This fact alone can make a difference in the company's success or failure.

Labor accidents and occupational diseases generate high and, why not say, unnecessary costs for companies. In addition, legal fees, employee absence, loss of raw materials and products can put in check the company's financial health. As a result, investing in prevention and regularization of occupational health and safety enables a healthier working environment, and further prevents future legal consequences.

In the work environment, it is possible to verify daily occupational risks. The occupational risks are divided into chemical risks, physical risks, biological risks, ergonomic risks and accident risks [1]. All risk groups are important and should be analysed by the company. However, risks are sometimes underestimated due to a lack of knowledge, especially chemical risk. For this reason, a properly trained professional is needed to identify possible sources of problems. 
A paper published in 2013 [2], corroborates the affirmation above. The publication presents a research about the researchers' safety in laboratories. It is possible to observe that highly qualified professionals are unaware of the chemical hazards in their work environment. Several chemical exposure consequences are described in numerous literatures, from minor inflammations to fatal consequences (intoxication and cancer). Professionals are trained to work in laboratories, where chemical agents are present without being aware of the risks they are exposed to. Furthermore, Ramazzini, in the seventeenth century, wrote about the workers' health problems due to contact with chemicals, dedicating a whole chapter of his book to the professional chemists' diseases, and another chapter for diseases with a higher incidence in pharmacists [3].

The development of Toxicology, a multidisciplinary science that studies the interaction between organisms and chemical agents capable of producing harmful responses, destroying life or compromising biological functions [4], has brought us a vast list of information that helps to control the work environment. The advancement in this area has brought information about occupational hygiene and helped to determine occupational exposure limits. In order to prevent the harmful effects from chemical substances, toxicology determine restrictions to be applied in several areas [5]. The proper application of exposure limits in occupational hygiene is intended to establish conditions for reduction or removal of adverse effects on workers [6].

Several countries determine exposure limits for some chemicals that should be monitored and controlled in the workplace to prevent accidents and occupational diseases. Exposure limits for chemical agents in Brazil can be found in Regulatory Norm number 15 (NR-15). This standard has tolerance limits for approximately 150 substances; this data has not been updated since the legislation was enacted in 1978 with the exception of carbon black and benzene. American Conference of Governmental Industrial Hygienists (ACGIH) is a professional association of industrial hygienists and related professions practitioners, located in Cincinnati, Ohio - United States of America. It catalogs tolerance limits for more than 600 substances, permanently under review. Given this, a company concerned about health and safety in Brazil should seek other sources of information besides the NR-15.

In addition to quantitative assessments, it is advisable to make qualitative assessments by analysing the Chemical Safety Data Sheets (MSDSs). The Jorge Duprat Figueiredo Foundation for Safety and Occupational Medicine (Fundacentro), located in Brazil, published in 2012 an evaluation methodology based on a methodology promoted by the International Labor Organization (ILO) and the World Health Organization (WHO). This methodology uses the Globally Harmonized System of Classification and Labelling of Chemicals (GHS) to determine the substances toxicity classification.

The GHS is a global classification system for hazardous chemicals developed under Agenda 21, a document created in Eco 92 (United Nations Conference on Environment and Development) held from June 3rd to June 14th, 1992 in Rio de Janeiro. The basic objective of hazard communication is to ensure that employers, employees and the public receive adequate, practical, reliable, comprehensive and understandable information about chemical hazards so that preventive and protective measures for health and safety could be taken [7], [8].

The World Summit on Sustainable Development (WSSD) held in Johannesburg 2002 encouraged countries to implement the GHS as soon as possible with a view to having the system fully operational by 2008 . In response to this statement, the activities to implement the GHS have been done all over the world [9]. The GHS application in Brazil is described in Ordinance no. 229 of the Ministry of Labor, requiring the classification, labeling and MSDS according to the GHS system, following a model established by Brazilian Standard 
(NBR) 14725 elaborated by the Brazilian Association of Technical Standards (ABNT). The ABNT NBR 14725 constitutes a part of the effort in the enforcement of the GHS in Brazil.

Chemical Abstracts Service (CAS) catalogs more than 129 million chemicals, it can be seen that the substances listed by ACGIH account less than $0.0005 \%$ of the total substances cataloged. Considering this, the qualitative evaluation becomes indispensable for chemical risk recognition in a work environment. Pharmaceutical industry laboratories, for example, deal with many substances every day. Several tests to ensure the quality of the products are made daily. For such evaluations, several Reference Standards (RS) are used. RS are highly characterized physical specimens used in testing by pharmaceutical and related industries to help ensure the identity, quality, strength and purity of drugs (pharmaceuticals, biologicals and excipients), dietary supplements, and food ingredients [10]. Due to the large number of standards in pharmaceutical laboratories, the management of hazards and risks is essential for the occupational exposure control.

Thus, it can be observed that the search for working conditions that minimize occupational risks, especially chemical risks in laboratories, are very important for the employees' health and safety.

\section{MATERIALS AND METHODS}

This paper presents a case study in a laboratory of a pharmaceutical industry. 357 RS were analysed in order to compare quantitative tolerance limits with qualitative risk analysis. The industry is located in Espírito Santo state, Brazil. The analysis procedure was divided into four distinctive phases.

\subsection{Inventory}

The inventory was made by collecting products lists supplied by the company and the MSDSs of the RS. The composition of each standard was done by analysing the MSDSs. From this, a list of the RS was generated, with the substances that compose them identified by the CAS number. This is a unique registration number in the Chemical Abstracts Service database, a division of the Chemical American Society, which is a chemical identity number.

\subsection{Qualitative analysis}

The qualitative analysis was done by associating the GHS hazard statements of RS [11], taken from their MSDSs, with the toxicity classification determined by the Fundacentro methodology. The GHS system classifies the substance or mixture by hazard pictograms, warning word (Attention or Danger), hazard classes, hazard statements (symbolized by a letter $\mathrm{H}$ and a number) and precautionary statements (symbolized by a letter $\mathrm{P}$ and a number).

The Fundacentro methodology is divided into five stages: the product toxicity determination, the amount used the identification of how the product spreads in the environment, the ascertainment of the appropriate control measure and finally the choice of the specific control sheets. For the present study, only the first stage of this methodology was employed because the objective was to identify the toxicity of the substances.

The first step, as already mentioned, is the toxicity identification; this is done by allocating a risk factor for each substance. In accordance with the principles of this approach, the chemical substances are divided into six distinct groups. Five of these groups, from A to E, are related to the health damage caused by inhalation or ingestion of the substances. Substances who present the greatest potential for causing health damage are classified in category E. Substances who have the lowest potential for causing health damage are allocated 
in category A, including those that do not have GHS classification. There is also a group S, which covers chemicals that can cause damage when in contact with skin or eyes. It must be verified if the RS are also allocated in this group [12]. The methodology provides a table linking the GHS with Groups A to E and S (Table 1).

To select the respective group, the GHS classification was taken from the MSDS and compared to the toxicity groups. It should be noted that some substances could be classified into more than one group. In this case, the group classification that represents the greatest potential to cause health damage must be selected.

\subsection{Cutaneous absorption}

The cutaneous absorption of the reference RS was also analysed by the qualitative methodology, NR-15 and ACGIH. When assessing a worker's exposure, it is important to consider all entry routes, because exposure limits only take into account respiratory exposure [6]. The skin is an effective barrier against the penetration of chemicals. However, some substances may have skin absorption [13]. In addition to the limits, ACGIH and NR-15 indicate when the substance can be absorbed into the skin and cause health damage. Through the qualitative evaluation, as already described, the risk of cutaneous absorption is indicated when the RS fits into the S group.

Table 1: Risk groups (qualitative methodology) compared to GHS.

\begin{tabular}{l|l}
\hline GROUP & GHS \\
\hline \multirow{4}{*}{ Acute Toxicity (oral, dermal, inhalation), category 5 } \\
Skin corrosion/irritation, category 2 and 3 \\
Serious eye damage/eye irritation, category 2 \\
All dust and vapors not allocated in groups B-E.
\end{tabular}


According to ACGIH 2014, the notation "Skin" (indicated on some substances) refers to the significant potential contribution of dermal exposure to total exposure. In cases where dermal application studies have shown that absorption may cause systemic effects, a "skin" rating should be considered. Given that, it is understood that substances listed by ACGIH or NR-15, even without the indication of skin absorption risk, may cause adverse effects even if less severe than systemic effects [14].

\subsection{Quantitative exposure limits}

The quantitative analysis was done by mapping de exposure limits in ACGIH 2014 and NR-15. NR-15 Annex 11 contains tolerance limits for less than 150 substances. This legislation, published in 1978, used the ACGIH 1977 exposure limits. This attachment has time weighted average limits (LT), ceiling values, and peak exposures (PE). The LT are determined for an 8-hour workday and a 48-hour workweek. Values ceilings bring a "+" sign in front of the value to indicate that these limits cannot be exceeded at any time. The PE, calculated by eqn (1) and Table 2 , should not be exceeded; otherwise, it will be considered a serious and imminent risk situation. Short-term PE above the LT should be controlled, even where they are within the recommended guidelines. Limiting short-term high exposures is intended to prevent rapidly occurring acute adverse health effects resulting from transient PE during a work shift [14]. This table was used for the substances that have no ceiling value.

$$
P E=L T \times D F
$$

where:

- PE represents the peak exposure,

- LT represents the exposure limit,

- DF represents the deviation factor.

Annex 13A was included in NR-15 in 1995. This annex introduces the concept of VRT-MPT (Technological Reference Value-Time weighted average). The VRT refers to a benzene concentration in the air considered technically feasible. The VRT should be considered as a reference for continuous improvement programs of working environment conditions. Compliance with VRT is mandatory and does not exclude health risks [1]. It is also a time-weighted limit, considering an 8-hour workday, but does not determine a weekly workload.

ACGIH publishes occupational exposure limits (TLVs) for chemical and physical agents, which should be used as a guide for professionals. These limits assist in the safe exposure levels analysis of these agents in the workplace.

Table 2: Deviation factor by NR-15.

\begin{tabular}{|c|c|}
\hline $\mathbf{L T}\left(\mathbf{p p m}\right.$ or $\left.\mathbf{~ m g} / \mathbf{m}^{\mathbf{3}}\right)$ & DF \\
\hline $\mathbf{0}-\mathbf{1}$ & 3 \\
\hline $\mathbf{1}-\mathbf{1 0}$ & 2 \\
\hline $\mathbf{1 0}-\mathbf{1 0 0}$ & 1.5 \\
\hline $\mathbf{1 0 0}-\mathbf{1 0 0 0}$ & 1.25 \\
\hline Over 1000 & 1.1 \\
\hline
\end{tabular}


The ACGIH TLVs are widely used and are derived by an expert committee of volunteers [15]. ACGIH has three categories of TLVs that are Threshold Limit Value-Time-Weighted Average (TLV-TWA), Threshold Limit Value-Short-Term Exposure (TLV-STEL), and Threshold Limit Value- Ceiling Value (TLV-C).

The TLV-TWA has the same concept as the NR-15 LT because, as already mentioned, the NR-15 LTs uses the ACGIH 1977 limits, but it considers a conventional 8-hour workday and a 40-hour workweek, to which it is believed that nearly all workers may be repeatedly exposed, day after day, for a working lifetime without adverse effect. The TLV-STEL is a 15-minute TWA exposure that should not be exceeded at any time during a workday, even if the 8-hour TWA is within the TLV-TWA. The TLV-STEL usually supplements the TLV-TWA where there are recognized acute effects from a substance whose toxic effects are primarily of a chronic nature; however, the TLV-STEL may be a separate, independent exposure guideline. The TLV-C is the concentration that should not be exceeded during any part of the working exposure [14].

For many substances with a TLV-TWA, there is no TLV-STEL; nevertheless, short-term PE above the TLV-TWA should be controlled. Transient increases in workers' exposure levels (short-term PE) may exceed 3 times the value of the TLV-TWA level for no more than 15 minutes at a time, on no more than 4 occasions spaced 1 hour apart during a workday, and under no circumstances should they exceed 5 times the value of the TLV-TWA level. In addition, the 8-hour TWA is not to be exceeded for an 8-hour work period [16].

The different working hours, makes necessary a limit correction. As mentioned, the NR-15 admits a 48-hour workweek, while ACGIH considers a 40-hour workweek. This limited revision is usually done by the equation developed by Brief and Scala, using a mathematical model that reduces the exposure limit adopted for 40 hours, multiplying it by a correction factor that takes into account the increase of the exposure time and the time reduction for worker's recovery [6], [12]. This correction was used on the ACGIH 1977 limits to publish the NR-15. This paper employed the same correction through eqn (2) and eqn (3).

$$
\begin{gathered}
L T=C F * T L V-T W A, \\
F C=\frac{40}{h} * \frac{168-h}{128},
\end{gathered}
$$

where:

- LT represents the exposure limit for a workweek greater than 40-hours,

- $\mathrm{CF}$ represents the correction factor,

- TLV-TWA represents the ACGIH 2014 exposure limit,

- $h$ represents the hours worked in a week.

It must be noted that TLV-STEL and TLV-C should not be adjusted as they indicate adverse effects of acute exposure; this means that exposure time does not influence those limits [16].

\section{RESULTS}

The analysis of the 357 RS verified that some products had more than one substance in their composition, resulting in more than one CAS number. Some CAS numbers appeared in more than one RS. 


\subsection{Qualitative analysis}

Checking the 357 MSDSs for risk factors allocation (groups A to E and S) was obtained the following results shown in Table 3 . It is possible to observe that 119 products fit into the $\mathrm{D}$ or $\mathrm{E}$ categories. This means that $33.33 \%$ of the RS are considered highly toxic by qualitative analysis.

Even though this paper did not go through all the steps in the methodology, for substances that fit into de group E, no matter the quantity used or how the product spreads in the environment, necessary specialized assistance will be necessary to define the security measures.

\subsection{Quantitative limits ACGIH 2014 and NR-15}

After analysing the ACGIH exposure limits, 30 RS had TLVs, and, considering repeated CAS numbers, there were 28 substances with TLVs. Some substances did not have the CAS number on the ACGIH list, but they did fit into a group of substances. Transplatin and cisplatin are platinum-containing compounds, fit into Platinum and soluble salts group. Potassium dichromate presents in its chemical formula valance-chromium (VI) falling into the group: Compounds of Cr VI soluble in water. M-cresol is an isomer of cresols, so belongs to the group: Cresol, all isomers. N, N-dimethylaniline, also named 2,6-xylidine, is one of the six isomers of xylyl and belongs to the group: Xylidine (mixture of isomers). Magnesium stearate, as you can see in the name, fits into the group: Stearates. Silver sulphadiazine falls into the group: Silver, and compounds.

According to NR-15, appendix 11 and appendix 13A, there are 14 RS with LT and PE or VRT, and removing the substances that are repeated in the RS, amount to 12 substances with tolerance limits. It can be concluded that, only $8.40 \%$ (30 RS) have substances in their composition listed by ACGIH and 3.92\% (14 RS) by NR-15.

Table 3: Reference Standards distribution in the risk factors.

\begin{tabular}{c|c|c}
\hline Risk factor & Reference Standards (UN) & Reference Standards (\%) \\
\hline A & 111 & $31.09 \%$ \\
\hline A and S & 48 & $13.45 \%$ \\
\hline B & 20 & $5.60 \%$ \\
\hline B and S & 18 & $5.04 \%$ \\
\hline C & 8 & $2.24 \%$ \\
\hline C and S & 33 & $9.25 \%$ \\
\hline D & 48 & $13.45 \%$ \\
\hline D and S & 25 & $7.00 \%$ \\
\hline E & 15 & $4.20 \%$ \\
\hline E and S & 31 & $8.68 \%$ \\
\hline
\end{tabular}


In order to compare ACGIH with NR-15, it is necessary to use a conversion factor, as mentioned before considering a 48-hour workweek. The benzene VRT does not need this conversion because the Brazilian legislation only determines an 8-hour workday and does not indicates a weekly workload. It is noted that all 12 substances listed by NR-15 have also been listed by ACGIH. It was expected, since NR-15 was based on ACGIH 1977.

Considering the 12 substances listed by NR 15, 10 substances have TLV-TWA at ACGIH (acetaldehyde only has TLV-C and ethyl alcohol only has TLV-STEL). Amongst them, three substances have LTs equal to TLV-TWA, which are methyl ethyl ketone, methyl alcohol and formic acid. The other seven substances in the ACGIH are more restricted. Exemplifying, the benzene VRT-MPT is $200 \%$ greater than the TLV-TWA. The largest value discrepancy was presented by trichloroethylene; LT is $1000 \%$ greater than TLV-TWA.

The PE of NR-15 and the PE that under no circumstances should be exceed of ACGIH were compared. This happened for four substances without TLV-STEL. It was noted that in one substance the values were the same (dichloromethane), and in the others (cyclohexane, chloroform, acetonitrile) the NR-15 was more restrictive. This was already expected due to how these values were calculated.

Even though TLV-STEL, TLV-C and NR-15 PE conceptually differ in some points, those will be compared because they represent limits for acute exposure effects. Of the 12 substances under discussion, seven of them "gained" a TLV-STEL throughout the ACGIH updates. They are 2-propanol, formic acid, ethyl alcohol, methyl alcohol, Benzene, methyl ethyl ketone, and trichloroethylene. Only acetaldehyde has TLV-C. It is noted that acetaldehyde in 1977 used to have a TLV-TWA which was replaced by a TLV-C probably because toxicological characteristics. Benzene, even having a TLV-STEL, will not be used in this comparison since Brazilian legislation does not bring a PE for this substance.

In two substances (2-propanol and ethyl alcohol), the limits are practically equal, in three substances (formic acid, methyl alcohol and methyl ethyl ketone) NR-15 is more restrictive, and in two compounds (trichloroethylene and acetaldehyde) ACGIH is more restrictive.

\subsection{Cutaneous absorption}

The qualitative analysis indicated 155 products as potential damaging when in contact with skin or eyes, that is, $43.42 \%$ of the total RS. While ACGIH 2014 lists nine $(2.5 \%)$ and NR-15 only three (0.8\%) RS (Fig. 1). The nine RS listed by ACGIH are: 1, 4-dioxane residual solvent class 2, 1,4-dioxane, methyl alcohol, benzene, m-cresol, N, N-dimethylaniline, naphthalene, travoprost and travoprost related compound A. The three products listed by NR15 are 2-propanol, methyl alcohol and benzene.

Some substances had their risk classification (cutaneous absorption) changed over the years. In 1977 ACGIH (NR-15) considered 2-propanol with potential damage when in contact with skin. However, 2-propanol no longer has the "Skin" notation by ACGIH 2014 and acetonitrile "acquired" this notation throughout the updates. These facts show us how important it is always keep up-to-date toxicological data of chemical substances.

\subsection{NR-15 limits and qualitative analysis}

In the qualitative analysis, it is not used the CAS number, because for this classification the composition of the product influences a lot in the risk factor definition. The $14 \mathrm{RS}$ that have substances listed by the NR-15, present different qualitative classification between them (Table 4). There are five RS framed in D or E groups of the 14 listed by NR-15, this is due to their carcinogenicity, reproductive toxicity or germ cell mutagenicity. They are 
acetaldehyde, methyl alcohol, benzene, dichloromethane and dichloromethane residual solvent class 2. The last two are given this classification due to the same substance. Even dichloromethane residual solvent class 2 has only $0.3 \%$ of dichloromethane; the risk factor is the same for dichloromethane at $100 \%$. This is because this chemical is potentially carcinogenic.

After analysing the products classified as highly toxic by the qualitative analysis (the 119 products that fit the risk factor D or E), only five were found to have some exposure limit listed by NR-15, that is, only $4.2 \%$ have an exposure limit in Brazilian legislation.

\subsection{ACGIH limits and qualitative analysis}

The Table 5 shows the risk classification of the 30 RS listed by ACGIH. There are 15 RS highly toxic (D or E) that contain substances listed by ACGIH; this is due to their carcinogenicity, reproductive toxicity, germ cell mutagenicity or respiratory sensitization. They are: 1, 4-dioxane residual solvent class 2, 1, 4-dioxane, vinyl acetate, potassium dichromate, acetaldehyde, acetylsalicylic acid, methyl alcohol, benzene, Cisplatin, naphthalene, prednisone tablets, silver sulfadiazine, transplatin, dichloromethane and dichloromethane residual solvent class 2 .

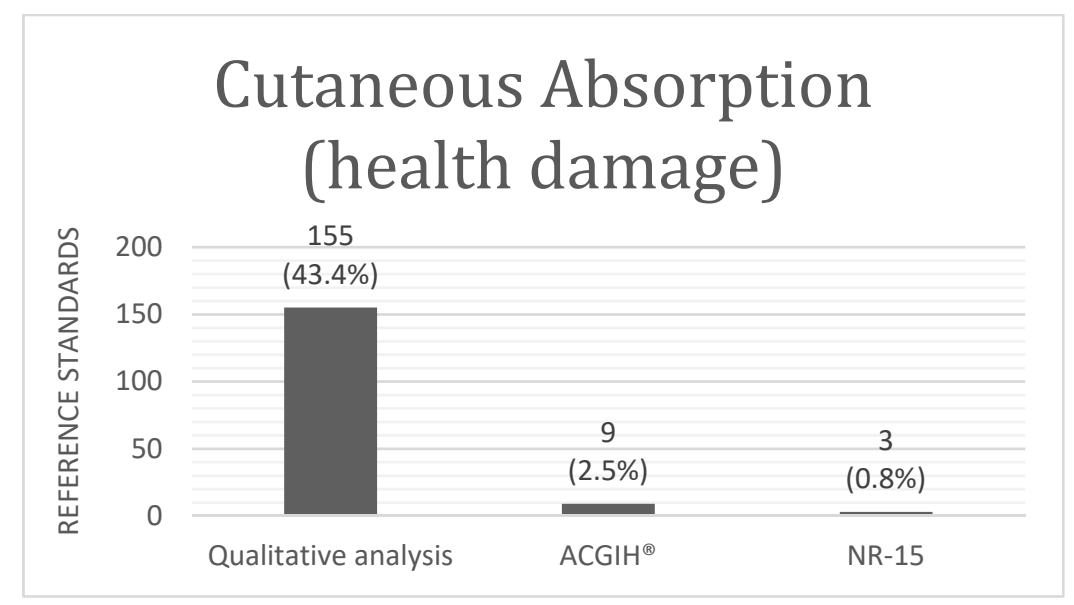

Figure 1: Reference Standards with potential damage due to skin absorption listed by qualitative assessment, NR-15 and ACGIH 2014.

Table 4: Reference Standards listed by NR-15 distribution in the risk factors.

\begin{tabular}{c|c|c}
\hline Risk factor & $\begin{array}{c}\text { Reference } \\
\text { Standards (UN) }\end{array}$ & $\begin{array}{c}\text { Reference } \\
\text { Standards (\%) }\end{array}$ \\
\hline A & 1 & $7.14 \%$ \\
\hline A and S & 5 & $35.71 \%$ \\
\hline B and S & 1 & $7.14 \%$ \\
\hline C and S & 2 & $14.29 \%$ \\
\hline D and S & 4 & $28.57 \%$ \\
\hline E and S & 1 & $7.14 \%$ \\
\hline
\end{tabular}


Table 5: Reference Standards listed by ACGIH distribution in the risk factors.

\begin{tabular}{c|c|c}
\hline Risk factor & $\begin{array}{c}\text { Reference } \\
\text { Standards } \\
\text { (UN) }\end{array}$ & $\begin{array}{c}\text { Reference } \\
\text { Standards } \\
(\mathbf{\%})\end{array}$ \\
\hline A & 2 & $6.67 \%$ \\
\hline A and S & 6 & $20.00 \%$ \\
\hline B and S & 3 & $10.00 \%$ \\
\hline C and S & 4 & $13.33 \%$ \\
\hline D & 1 & $3.33 \%$ \\
\hline D and S & 8 & $26.67 \%$ \\
\hline E and S & 6 & $20.00 \%$ \\
\hline
\end{tabular}

Among the products that fit the risk factor D or E (119 RS), 15 have some exposure limit listed by ACGIH, that is, only $12.6 \%$ have a quantitative reference by the American institution.

\section{CONCLUSION}

The present work shows that for a good chemical management, quantitative and qualitative analyses must be done together. This is concluded because several substances have no quantitative exposure limits and their toxicological effects are unknown, making chemical risk analysis purely quantitative is insufficient to guarantee the workers' health and safety.

After analysing the quantitative limits for the $357 \mathrm{RS}$, it was found that only $8.4 \%$ have substances listed by ACGIH and only 3.9\% have substances listed by NR-15. However, for RS classified as D or E (119 RS), only $4.2 \%$ have substances cited by NR-15 and $12.6 \%$ have substances listed by ACGIH 2014. This data show that even without quantitative limits, preventive measures for the workers' exposure must be ensured.

Among substances with TWA, it is noted that $70 \%$ of the NR-15 LTs mentioned in this paper have a lag in relation to ACGIH 2014 TLVs. Although, in some limits that consider acute effects, NR-15 is more restrictive, it should be considered that this is a legislation that has not changed in its occupational exposure limits since 1978, making its limits outdated by the evolution of data in this area. ACGIH TLVs, on the other hand, are subject to change every year, with professionals in the field who review data and compile scientific information constantly.

Another fact to consider is skin exposure. By the qualitative evaluation, almost half (43.4\%) of the $357 \mathrm{RS}$ presented risks when in contact with skin and very few are mentioned by ACGIH (nine RS - 2.5\%) and NR-15 (three RS - 0, 8\%). The notation "Skin" present in ACGIH and NR-15 only indicates substances that can cause serious and systemic effects while the qualitative evaluation also indicates irritating effects. This again shows the importance of quantitative and qualitative assessments together.

For companies concerned about their employees' health and safety, it is essential to consider up-to-dated information about occupational health. Even if in Brazil the law only requires the NR-15 exposure limits, companies should be aware of information provided by institutions such as ACGIH to avoid health risks to their workers. 


\section{REFERENCES}

[1] Regulatory Norms, Ministry of Labour, Brazil, Online. www.trabalho.gov.br/ index.php/seguranca-e-saude-no-trabalho/normatizacao/normas-regulamentadoras.

Accessed on: 20 Feb. 2016.

[2] Noorden, R.V., Safety survey reveals lab risks. Nature, 493, pp. 9-10, 2013.

[3] Melo, M.G.M., Study of dermatoses in workers of a pharmaceutical industry. Master's thesis, Oswaldo Cruz Foundation: São Paulo, 1999.

[4] Pesticides Toxicology, Endemics Control Superintendence of São Paulo, Online. www.saude.sp.gov.br/resources/sucen/programas/arquivos-seguranca-do-trabalho/ sequi5.pdf. Accessed on: 1 Feb. 2016.

[5] Buschinelli, J.T., Handbook on Occupational Medical Exposure Control for Chemical Substances, Fundacentro: São Paulo, 2014.

[6] Torloni, M. \& Vieira, A.V., Respiratory Protection Manual, ABHO: São Paulo, 2003.

[7] Brazilian Chemical Industry Association, What is GHS? Globally harmonized system of classification and labelling of chemicals, ABIQUIM/DETEC: São Paulo, 2005.

[8] Lee, S.W., Oh, S.Y. \& Kim, T.G., Overview of GHS (Globally Harmonized System) in Korea and the direction of further development. Journal of Loss Prevention in the Process Industries, 26(5), pp. 904-907, 2013.

[9] Jonai, H., Implementation of the GHS in Japan. Industrial Health, 46, pp. 443-447, 2008.

[10] Reference Standards, U.S. Pharmacopeial convention, Online. www.usp.org/ reference-standards. Accessed on: 24 Jan. 2016.

[11] United Nations, Globally Harmonized System of Classification and Labelling of Chemicals (GHS). UN: New York and Geneva, 2011.

[12] Ribeiro, M.G., Pedreira Filho, R. \& Riederer, E.E., Qualitative Chemical Risk Assessment: Basic Guidelines for the Control of Chemical Exposure, Fundacentro: São Paulo, 2012.

[13] Ruppenthal, J.E., Toxicology, UFSM/CTISM: Santa Maria, 2013.

[14] Association Advancing Occupational and Environmental Health, Threshold limit values for chemical substances and physical agents and biological exposure indices, Cincinatti: ACGIH, 2014.

[15] Deveau, M., Maier, A. \& Krewski, D., Application of a framework for the selection of an appropriate occupational exposure limit for manganese. NeuroToxicology, 58, pp. 249-256, 2017.

[16] Hofstadler, N. \& Ferreira, L.S., Occupational Hygiene III, UFSM/CTISM: Santa Maria, 2013. 